\title{
Resveratrol inhibits the invasion and metastasis of colon cancer through reversal of epithelial- mesenchymal transition via the AKT/GSK-3ß/Snail signaling pathway
}

\author{
LI YUAN $^{1 *}$, MENGMENG ZHOU $^{2 *}$, DAWEI HUANG ${ }^{3}$, HARPREET S. WASAN $^{4}$, KAI ZHANG $^{1}$, \\ LEITAO SUN ${ }^{1}$, HONG HUANG $^{5}$, SHENGLIN MA $^{6}$, MINHE SHEN ${ }^{7}$ and SHANMING RUAN ${ }^{6,7}$ \\ ${ }^{1}$ The First Clinical Medical College of Zhejiang Chinese Medical University, Hangzhou, Zhejiang 310053; \\ ${ }^{2}$ Department of Traditional Chinese Medicine, The First People's Hospital of Quzhou, Quzhou, Zhejiang 324000; \\ ${ }^{3}$ Department of Chinese Medicine, The First Affiliated Hospital of Zhejiang Chinese Medical University, \\ Hangzhou, Zhejiang 310006, P.R. China; ${ }^{4}$ Department of Cancer Medicine, Hammersmith Hospital, \\ Imperial College Healthcare NHS Trust, London W12 0HS, UK; ${ }^{5}$ Teaching and Research Section of Prescription, \\ Basic Medical College, Zhejiang Chinese Medical University, Hangzhou, Zhejiang 310053; ${ }^{6}$ Department of Medical Oncology, \\ The Fourth Affiliated Hospital of Zhejiang Chinese Medical University; ${ }^{7}$ Department of Medical Oncology, \\ The First Affiliated Hospital of Zhejiang Chinese Medical University, Hangzhou, Zhejiang 310006, P.R. China
}

Received February 11, 2019; Accepted June 6, 2019

DOI: $10.3892 / \mathrm{mmr} .2019 .10528$

\begin{abstract}
The identification of safe and effective drugs that inhibit tumor invasion and metastasis is required to improve the clinical outcome of patients with colon cancer. The present study aimed to investigate the inhibitory effects and possible mechanisms of action of resveratrol against the invasion and metastasis of colon cancer. AKT1-knockdown SW480 and SW620 colon cancer cells were used to detect the effects of resveratrol on cell invasion and metastasis, as well as changes in the expression of epithelial-mesenchymal transition (EMT) markers and serine/threonine kinase (AKT)/glycogen synthase kinase (GSK)-3 $\beta /$ Snail signaling pathway-related molecules in vitro. Furthermore, nude mice were inoculated with SW480 cells in the tail vein to establish an in vivo lung metastasis
\end{abstract}

Correspondence to: Professor Shanming Ruan, Department of Medical Oncology, The First Affiliated Hospital of Zhejiang Chinese Medical University, 54 Youdian Road, Shangcheng, Hangzhou, Zhejiang 310006, P.R. China

E-mail: shanmingruan@zcmu.edu.cn

${ }^{*}$ Contributed equally

Abbreviations: EMT, epithelial-mesenchymal transition; CRC, colorectal cancer; E-cad, E-cadherin; N-cad, N-cadherin; AKT, serine/threonine kinase; EGF, epidermal growth factor; HCC, human colon cancer; FBS, fetal bovine serum; CCK-8, Cell Counting Kit-8; IR, inhibition rate; H\&E, hematoxylin and eosin; TCM, Traditional Chinese Medicine

Key words: colon cancer, resveratrol, metastasis, epithelialmesenchymal transition; AKT/GSK-3 $\beta /$ Snail signaling model of colon cancer, to investigate the effects of resveratrol on lung metastasis in colon cancer. The results revealed that resveratrol treatment and AKT1 knockdown significantly inhibited cell migration and invasion in colon cancer, and markedly increased E-cadherin expression and decreased that of $\mathrm{N}$-cadherin, phospho (p)-AKT1, p-GSK-3 $\beta$, and Snail in colon cancer both in vitro and in vivo. Furthermore, the effects of resveratrol were significantly weaker in the AKT1-knockdown cells. In conclusion, resveratrol may suppress the invasion and metastasis of colon cancer through reversal of EMT via the AKT/GSK-3 $3 /$ Snail signaling pathway. AKT1 may therefore be a key regulator of EMT in colon cancer cells and a potential therapeutic target for this disease.

\section{Introduction}

Colorectal cancer (CRC) is one of the most common malignancies worldwide with high incidence and mortality $(1,2)$. It is estimated that the global burden of CRC will increase by $60 \%$ by 2030 (3). In addition, the survival rates of patients with CRC with local and distant metastases are $71 \%$ and $14 \%$, respectively (4). Despite the major advances in diagnosis and treatment, approximately $50 \%$ of patients with CRC experience recurrence and succumb to this disease within 5 years $(5,6)$. Tumor invasion and metastasis in the middle and late stages are the root causes of treatment failure and poor therapeutic efficacy $(7,8)$. Hence, to improve the clinical outcome for patients with CRC, it is imperative to identify safe and effective drugs for the inhibition of tumor progression.

Resveratrol (3,5,4'-trihydroxystilbene), a phytoalexin, is found in many plants, such as grapes, peanuts, and berries. Evidence has confirmed that resveratrol offers protection against several human diseases, such as metabolic diseases 
and various cancers $(9,10)$. In recent years, an increasing number of studies have revealed that resveratrol can regulate tumor cell migration and invasion through modulation of epithelial-mesenchymal transition (EMT) in various cancers, such as oral squamous cell carcinoma (11), glioma (12), and pancreatic cancer (13). In the malignant progression of tumors, EMT is known to cause loss of mutual adhesion between tumor cells, and therefore, lead to enhanced invasion and movement ability (14). Serine/threonine kinase (AKT) is closely related to the occurrence of EMT $(15,16)$, and is involved in many biological and pathological processes, such as angiogenesis, invasion, and metastasis (17). In addition, the glycogen synthase kinase (GSK)-3 $\beta$ pathway is the classical downstream pathway of AKT, and often participates in the development of EMT with AKT (18). Furthermore, Snail expression can be regulated via the AKT/GSK-3 $\beta$ signaling pathway (19), and activation of this pathway may promote EMT in hepatoma cells (20) and ovarian clear cell carcinoma cells (21). However, it is unclear whether the AKT/GSK-3/Snail signaling pathway is a key mechanism in the regulation of EMT by resveratrol.

In the present study, stable AKT1 knockdown was successfully established in colon cancer cells and an animal model of lung metastasis of colon cancer. Subsequently, the inhibitory effects and possible mechanism of action of resveratrol against invasion and metastasis of colon cancer both in vitro and in vivo were explored. These findings may provide new strategies for colon cancer treatment.

\section{Materials and methods}

Cell culture. The adherent human colon cancer cell lines SW480 and SW620 were obtained from the Cell Bank of the Chinese Academy of Sciences. SW480 cells were cultured in RPMI-1640 medium (Kino Biological and Pharmaceutical Technology Co., Ltd.) supplemented with $10 \%$ fetal bovine serum (FBS; Thermo Fisher Scientific, Inc.) and maintained at $37^{\circ} \mathrm{C}$ in a humidified atmosphere with $5 \% \mathrm{CO}_{2} . \mathrm{SW} 620$ cells were grown in L-15 medium (Kino Biological and Pharmaceutical Technology Co., Ltd.) supplemented with $10 \%$ FBS in an incubator with the same culture conditions.

Construction of lentivirus vectors for AKT1 knockdown and generation of stably infected SW480 and SW620 cell lines. Lentivirus vectors for small interfering RNA (siRNA) were constructed to explore the function of AKT1 with assistance from Shanghai GeneChem Co., Ltd. Three AKT1-siRNAs were designed and used, with the following sequences: Sequence 1, gaTCCTCAAGAAGGAAGTCAT; sequence 2, gcATCGCTT CTTTGCCGGTAT; and sequence 3, ggACAAGGACGG GCACATTAA. After annealing, the double oligonucleotides obtained were inserted into the AgeI/EcoRI sites of the GV248 lentiviral vector with green fluorescent protein (GFP; Shanghai GeneChem Co., Ltd.). Moreover, one scrambled RNA (sequence, TTCTCCGAACGTGTCACGT) was used as the negative control (NC) and cloned into the GV248 lentiviral vector (Shanghai GeneChem Co., Ltd.). After identification and lentivirus packaging, SW480 and SW620 cells were infected with the acquired lentiviruses [multiplicity of infection $(\mathrm{MOI})=10$ ] for $16 \mathrm{~h}$. After infection for $72 \mathrm{~h}, \mathrm{SW} 480$ and
SW620 cells were harvested, and the knockdown efficiency of AKT1 was detected by reverse transcription polymerase chain reaction (RT-PCR) and western blotting.

Epidermal growth factor (EGF)-induced EMT model. Treatment with various concentrations $(10,25,50$, and $100 \mathrm{ng} / \mathrm{ml}$ ) of EGF (R\&D Systems, Inc.) has been revealed to induce EMT in SW480 cells $(22,23)$. Therefore, SW480 and SW620 cells seeded at a density of $1 \times 10^{6}$ were treated with $50 \mathrm{ng} / \mathrm{ml}$ EGF for $48 \mathrm{~h}$ to establish an EMT model. Expression of E-cadherin, N-cadherin, and vimentin were then detected to confirm the success of the EGF-induced EMT model. Subsequent experiments were then conducted using this model.

Cell viability assay. The viability of SW480 and SW620 cells was estimated using a Cell Counting Kit-8 (CCK-8) (Nanjing KeyGen Biotech Co., Ltd.). Briefly, $1 \times 10^{6}$ cells/well were seeded in 96-well plates and incubated until the cells reached $60 \%$ confluence. Resveratrol (Sigma-Aldrich; Merck KGaA) was then added at different concentrations $(0,7.5,15,30,60$, 120 , and $240 \mu \mathrm{mol} / \mathrm{l})$ to the cells and incubated for $48 \mathrm{~h}$. Cells were further incubated with CCK- 8 reagent for $2 \mathrm{~h}$, followed by optical density (OD) measurement at a wavelength of $450 \mathrm{~nm}$ using a microplate reader (BioRad Laboratories, Inc.). In addition, inhibition of SW480 and SW620 cell proliferation at various treatment concentrations was calculated using the following formula: Proliferation inhibition rate $(\%)=($ average OD in all control group duplicates-average OD in the treatment group)/average OD in the blank control group x100\%.

Scratch wound healing experiment. SW480 and SW620 cells were plated at densities of $2 \times 10^{5}$ and $3.5 \times 10^{5}$, respectively, into 6-well plates. After treatment, cells were cultured until the well bottoms were fully covered. Subsequently, a cell-free gap was created by scratching the well bottom using a $200-\mu 1$ pipette tip. The debris produced after scratching was removed by rinsing with phosphate-buffered saline (PBS). Subsequently, $3 \mathrm{ml}$ serum-free medium was added to the culture plates and the cells were incubated for $24 \mathrm{~h}$ at $37^{\circ} \mathrm{C}$ in an incubator with $5 \% \mathrm{CO}_{2}$. Finally, cell migration was observed in 3-5 randomly selected fields using an optical microscope (IX71; $\mathrm{x} 100$, magnification; Olympus Corporation) and the migration distance over $24 \mathrm{~h}$ (in pixels) was evaluated using Image-Pro Plus software version 6 (Media Cybernetics, Inc.).

Transwell migration and invasion (Matrigel) experiment. The migration and invasion of SW480 and SW620 cells were evaluated using Transwell assays. For cell invasion, $40 \mu \mathrm{l}$ diluted Matrigel glue (Corning Incorporated) was evenly spread in the upper chamber (24-well) and allowed to solidify. Briefly, after the different treatments were completed, $2 \times 10^{6} \mathrm{SW} 480$ and SW620 cells were resuspended in $200 \mu \mathrm{l}$ serum-free medium and plated in the upper chamber of each Transwell (6.5 mm insert; $8.0 \mu \mathrm{m}$ polycarbonate membrane; Corning Incorporated). Subsequently, $600 \mu 1$ complete medium (containing $10 \%$ FBS) was placed into the lower chamber. After incubation for $48 \mathrm{~h}$ at $37^{\circ} \mathrm{C}$ in a $5 \% \mathrm{CO}_{2}$ incubator, migrated or invaded cells that passed through the membranes were fixed in $4 \%$ paraformaldehyde (Wuhan Boster Biological 
Technology, Ltd.) for 20 min, washed once with PBS, and stained with $0.1 \%$ crystal violet (Sangon Biotech Co., Ltd.) for $30 \mathrm{~min}$. Finally, images of the migrated and invaded cells were photographed and counted using a microscope (ix71; Olympus Corporation, x200, magnification).

Real-time quantitative PCR ( $q P C R)$. Following treatment, total RNA was extracted from the cells using TRIzol reagent (Shanghai Pufei Biotech Co., Ltd.). Reverse transcription into cDNA was then performed using the M-MLV Reverse Transcriptase kit (Promega Corporation). Real-time qPCR was used to detect the expression of each target gene and the internal reference glyceraldehyde 3-phosphate dehydrogenase (GAPDH). Each reaction was performed in $12 \mu \mathrm{l}$ reaction mixture, containing $0.6 \mu 1$ template cDNA, $0.3 \mu 1$ primer mix (5 $\mu \mathrm{M}), 6 \mu \mathrm{l}$ SYBR Premix Ex Taq (Takara Bio, Inc.), and $5.1 \mu \mathrm{l}$ RNase-Free $\mathrm{H}_{2} \mathrm{O}$. The reaction conditions of RT-qPCR were as follows: $95^{\circ} \mathrm{C}, 3 \mathrm{~min}$, pre-modification; $95^{\circ} \mathrm{C}, 3 \mathrm{sec}$, annealing; $60^{\circ} \mathrm{C}, 30 \mathrm{sec}$, extension; intermediate cycle 40 times. The forward and reverse sequences of primers used for gene amplification were as follows: GAPDH (121 bp): 5'-TGACTT CAACAGCGACACCCA-3' and 5'-CACCCTGTTGCTGTA GCCAAA-3'; AKT1 (287 bp): 5'-GTGCTGGAGGACAATGA CTAC-3' and 5'-TGCTGCCACACGATACCG-3', respectively. The relative expression of each gene was calculated using the $2^{-\Delta \Delta \mathrm{Cq}}$ method (24).

Western blotting. Following different treatments, total protein was extracted from cells or tissues using radioimmunoprecipitation (RIPA) lysis buffer (Beyotime Institute of Biotechnology). Equal amounts of protein extracts $(\sim 20 \mu \mathrm{g})$ were subjected to $10 \%$ sodium dodecyl sulfate-polyacrylamide gel electrophoresis (SDS-PAGE), and the protein bands were transferred to a polyvinylidene fluoride (PVDF) membrane (EMD Millipore). Following non-specific binding the membrane was blocked by incubation with Tris-buffered saline with Tween-20 ${ }^{\circledR}$ (TBST) containing 5\% skimmed milk powder, and the membranes were then probed with appropriate primary antibodies at $4^{\circ} \mathrm{C}$ overnight and incubated again with a corresponding secondary horseradish peroxidase (HRP)-conjugated antibody for $1 \mathrm{~h}$. AKT1 (cat. no. 4691S; 1:1,000), p-AKT (Ser473) (cat. no. 4060S; 1:1,000), GSK-3 $\beta$ (cat. no. 9315S; 1:1,000), p-GSK-3 $\beta$ (Ser9) (cat. no. 5558P; 1:1,000) and Snail (cat. no. 3879S; 1:500) were obtained from Cell Signaling Technology, Inc. N-cadherin (cat. no. 76011; 1:500) and E-cadherin (cat. no. 76319; 1:1,000) were purchased from Abcam, and $\beta$-actin (cat. no. 20536-1-AP; 1:1,000) was purchased from ProteinTech Group, Inc. Peroxidase Conjugated Goat anti-Mouse IgG (H+L) (cat. no. DW0990; 1:1,000), and Peroxidase Conjugated Goat anti-Rabbit IgG $(\mathrm{H}+\mathrm{L})$ (cat. no. DW-GAR007; 1:1,000) were purchased from Hangzhou Dawen Biology Co., Ltd. To visualize the bands, enhanced chemiluminescence solution (ECL; Thermo Fisher Scientific, Inc.) was added, and the integral OD of each protein band was analyzed using Image-Pro Plus version 6 software. $\beta$-actin was used as the internal control.

Establishment of an in vivo tumor xenograft model. In accordance with the protocols for experimentation with animals (National Institutes of Health Publication; no. 85-23, revised
1996), animal experiments conducted were approved by the Institutional Animal Care and Use Committee of Zhejiang Chinese Medical University [Laboratory Animals Production License No. SCXK (Shanghai) 2013-0006, Shanghai Xipuer-Bikai Experimental Animal Co. Ltd.; Laboratory Animals Usage License No. SYXK (Zhejiang) 2013-0184, Animal Experimental Research Center, Zhejiang University of Traditional Chinese Medicine. In total, 32 male, 4-week-old $\mathrm{BALB} / \mathrm{c}(\mathrm{nu} / \mathrm{nu})$ mice weighing $15 \pm 1 \mathrm{~g}$ were obtained from Shanghai Xipuer-Bikai Experimental Animal Co., Ltd. The mice were fed a normal diet and water and were housed in a specific pathogen-free (SPF) barrier center under constant conditions (temperature, $25 \pm 2{ }^{\circ} \mathrm{C}$; humidity, $50 \pm 5 \%$; 12-h light/dark cycles).

SW480 cells transfected with si-AKT1 or NC were collected, and the density was adjusted to $3 \times 10^{7}$ cells $/ \mathrm{ml}$ with normal saline. Each nude mouse was inoculated with $0.2 \mathrm{ml}$ cell suspension into the tail vein to establish a lung metastasis model of colon cancer $(25,26)$. Two weeks after inoculation, disease progression was assessed using live fluorescence imaging. Nude mice were further divided into control groups (NC-control and si-AKT1-control) and resveratrol groups (NC-resveratrol, si-AKT1-resveratrol) according to the total flux in in vivo imaging. During the experiment, the activity of the nude mice was observed, they were weighed daily, and the mice underwent intragastric administration according to their body weight. Nude mice in the resveratrol groups received $150 \mathrm{mg} / \mathrm{kg}$ resveratrol via gavage once daily for 2 weeks. Mice in the control groups received an equal volume of normal saline once daily for 2 weeks. Subsequently, after the last intragastric administration, and fasting and water prohibition for $4 \mathrm{~h}$, lung metastasis was detected using live cell fluorescence imaging technique. The nude mice were then sacrificed by cervical dislocation and the tumor foci and lung tissue were collected for subsequent experiments.

In vivo bioluminescence imaging. For in vivo bioluminescence imaging, the mice were intraperitoneally injected with $150 \mathrm{mg} / \mathrm{kg}$ body weight D-luciferin (cat. no. 40901ES03; $15 \mathrm{mg} / \mathrm{ml}$, Yeasen Corp.) in normal saline. In vivo imaging was performed half an hour after intraperitoneal injection of D-luciferin. Luminescence image acquisition was conducted using a cooled charge-coupled device (CCD) camera system (IVIS Imaging System; PerkinElmer, Inc.) with an integration time of 1-60 sec and a binning factor of 4. During imaging, the nude mice were anesthetized by continuously inhaling $2 \%$ isoflurane (cat. no. O21400; Huazhong Haiwei Gene Technology Co., Ltd.). The flux of all detected photon counts within a region of interest prescribed over the tumor area was collected to calculate the signal intensity using the Living Image software package (Xenogen Corporation).

Hematoxylin and eosin $(H \& E)$ staining and immunohistochemistry. The tumor tissues obtained were fixed in paraformaldehyde at $4^{\circ} \mathrm{C}$ for $24 \mathrm{~h}$, dehydrated in ethanol, treated with xylene, embedded in paraffin, and sliced. Tissue slices of 4- $\mu \mathrm{m}$ thickness were subjected to H\&E staining (cat. no. ZLI-9609; ZSGB-BIO; OriGene Technologies, Inc.) and histological changes in the tumor tissues were observed using a microscope (ix71; Olympus Corporation; x200, magnification). 
Table I. IR of SW480 and SW620 cell lines treated with various concentrations of resveratrol for $48 \mathrm{~h}(\mathrm{X} \pm \mathrm{S}, \mathrm{n}=9)$.

\begin{tabular}{lcccccccc}
\hline Concentration $(\mu \mathrm{M})$ & 0 & 3.75 & 7.5 & 15 & 30 & 60 & 120 & 240 \\
\hline IR $(\%)$ in SW480 cells & $-1.21 \pm 2.96$ & $0.93 \pm 3.18$ & $3.04 \pm 1.95$ & $4.39 \pm 3.32$ & $26.43 \pm 6.23$ & $67.32 \pm 6.91$ & $86.11 \pm 4.07$ & $92.88 \pm 4.24$ \\
IR (\%) in SW620 cells & $1.39 \pm 3.37$ & $1.51 \pm 3.69$ & $3.06 \pm 1.91$ & $3.83 \pm 2.99$ & $21.77 \pm 4.29$ & $58.73 \pm 3.16$ & $83.57 \pm 3.09$ & $92.69 \pm 5.66$ \\
\hline
\end{tabular}

IR, inhibition rate.

For immunohistochemistry staining, $4 \mu \mathrm{m}$-thick tissue slices were immersed in $1 \mathrm{mM}$ ethylenediaminetetraacetic acid (EDTA) buffer $(\mathrm{pH}=9.0)$ for antigen retrieval. After removal of endogenous peroxidase activity with $3 \% \mathrm{H}_{2} \mathrm{O}_{2}$, non-specific protein binding was blocked with $5 \%$ normal goat serum buffer at $37^{\circ} \mathrm{C}$ for $30 \mathrm{~min}$. Samples were incubated at $4^{\circ} \mathrm{C}$ overnight with primary antibodies, including $\mathrm{N}$-cadherin antibody (cat. no. 76011; 1:300), E-cadherin rabbit monoclonal antibody (mAb; cat. no. 76319; 1:300), AKT1 rabbit mAb (cat. no. 4691S; 1:300), p-AKT (Ser473; cat. no. 4060S; 1:300), GSK-3 $\beta$ polyclonal antibody (cat. no. 9315S; 1:300), p-GSK-3 $\beta$ (Ser9; cat. no. 5558P; 1:300), and Snai1 polyclonal antibody (cat. no. 3879S; 1:300). Next, the slides were incubated first with biotin-labeled goat-rabbit immunoglobulin $\mathrm{G}(\operatorname{IgG})$, followed by HRP-conjugated streptavidin for $1 \mathrm{~h}$ each. The reaction products were visualized after staining with diaminobenzidine (DAB; cat. no. ZLI-9065, ZSGB-BIO; OriGene Technologies, Inc.) with a concentration of $2 \mathrm{mg} / \mathrm{ml}$ at room temperature for $10 \mathrm{~min}$ and counterstaining with hematoxylin. The results were observed and images were captured using an inverted microscope (x200, magnification), followed by analysis of the total integral optical density (IOD) using Image-Pro Plus version 6 software.

Statistical analysis. The data are presented as the means \pm standard deviation (SD) and the distribution of the data was assessed. All statistical analyses were computed using SPSS version 22.0 software (IBM Corp.). For data that were normally distributed, significant differences between the groups were evaluated via one-way analysis of variance (ANOVA) followed by Tukey's multiple comparison test. For data that did not conform to a normal distribution, the Kruskal Wallis $\mathrm{H}$ test was used. A value of $\mathrm{P}<0.05$ indicated statistical significance. All experiments were repeated three times.

\section{Results}

AKT1 is successfully knocked down in SW480 and SW620 cells, and EGF successfully induces EMT in both cell lines. For AKT1 knockdown, lentivirus vectors containing si-ATK1 and NC were injected into SW480 and SW620 cells. As revealed in Fig. 1A, the transfection of any of the three si-ATK1 sequences significantly inhibited the expression of AKT1 $(\mathrm{P}<0.01$ and $\mathrm{P}<0.001)$. The knockdown efficiency of sequence 1 was the highest and this was, therefore, selected for subsequent experiments. In addition, the expression of AKT1 mRNA in SW480 and SW620 cells transfected with si-AKT1 was significantly decreased compared with that in the two cell lines transfected with $\mathrm{NC}(\mathrm{P}<0.001$, Fig. 1B). Furthermore, western blotting confirmed consistent changes in AKT1 protein expression after knockdown $(\mathrm{P}<0.01$, Fig. $1 \mathrm{C}$ and $\mathrm{D})$. Thus, stable AKT1-knockdown cell lines were successfully established in SW480 and SW620 colon cancer cells.

In addition, EGF was used to induce EMT in both cell lines. Western blotting revealed that E-cadherin expression in both cell lines was markedly downregulated after treatment with $50 \mathrm{ng} / \mathrm{ml} \mathrm{EGF}$, whereas the expression of $\mathrm{N}$-cadherin and vimentin was significantly upregulated $(\mathrm{P}<0.05$ and $\mathrm{P}<0.01$, Fig. 1E-G). These data indicated that the EMT model was successfully established by EGF in both cell lines.

Cytotoxic effects of resveratrol on colon cancer cells. As revealed in Fig. 2A, cells were treated with resveratrol at concentrations of $3.75,7.5,15,30,60,120$, and $240 \mu \mathrm{M}$. The half maximal inhibition concentration $\left(\mathrm{IC}_{50}\right)$ of resveratrol was $69.58 \mu \mathrm{M}$ in SW480 cells and $77.24 \mu \mathrm{M}$ in SW620 cells (Table I).

As revealed in Fig. 2B, resveratrol significantly decreased the cell survival rate of SW480 and SW620 cells doses $>30 \mu \mathrm{M}$ $(\mathrm{P}<0.001)$. In addition, the inhibitory effects increased in a dose-dependent manner. Accordingly, the maximum nontoxic concentration of resveratrol was defined as $15 \mu \mathrm{M}$ and was used in subsequent experiments.

Resveratrol inhibits the migration and invasion of colon cancer cells in vitro, and knockdown of AKTl exhibits similar effects. Whether the effects of resveratrol on cell migration and invasion were achieved via AKT1 regulation was then assessed. The scratch wound healing assay revealed that the 24-h migration distance of two cell lines in the NC-resveratrol group was significantly shorter than that in NC-control group $(\mathrm{P}<0.001$, Fig. 3$)$, indicating that resveratrol inhibited the healing ability of colon cancer cells. The 24-h migration distance of cells in the si-AKT1-control group was also significantly shorter than that in NC-control group $(\mathrm{P}<0.001$, Fig. 3), indicating that AKT1 knockdown also inhibited the healing ability of colon cancer cells. However, no significant difference was observed between the 24-h migration distance in the si-AKT1-control and si-AKT1-resveratrol groups $(\mathrm{P}>0.05$, Fig. 3), indicating that the ability of resveratrol to inhibit the healing ability of colon cancer cells was weakened or even nullified in AKT1-knockdown cells.

Transwell assays were also performed to detect the migration and invasion of both cell lines (Fig. 4). The number of migrated and invaded cells passing through the membrane in the NC-resveratrol group was significantly lower than that in the NC-control group $(\mathrm{P}<0.001)$, indicating that resveratrol markedly inhibited the migration and invasion of colon cancer cells. In addition, the number of migrated and invaded cells passing through the membrane in the si-AKT1-control group 
A

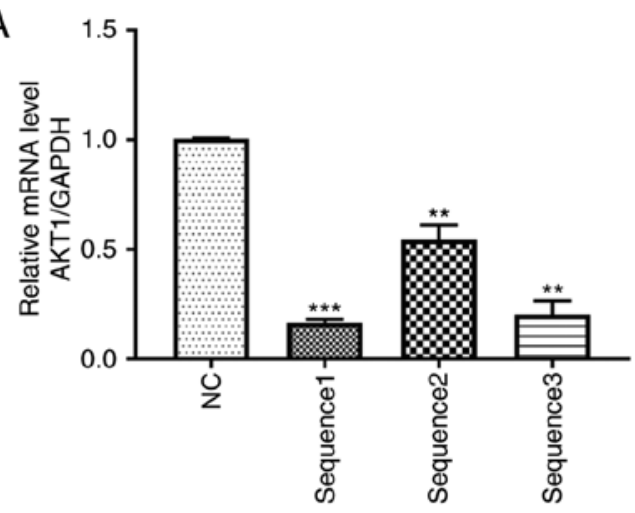

C

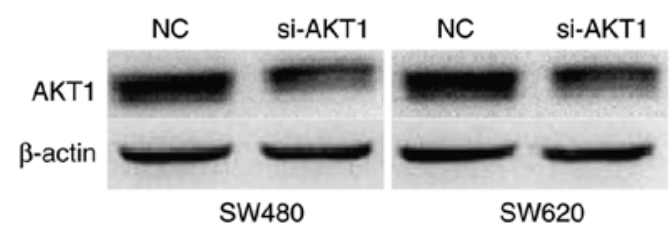

B

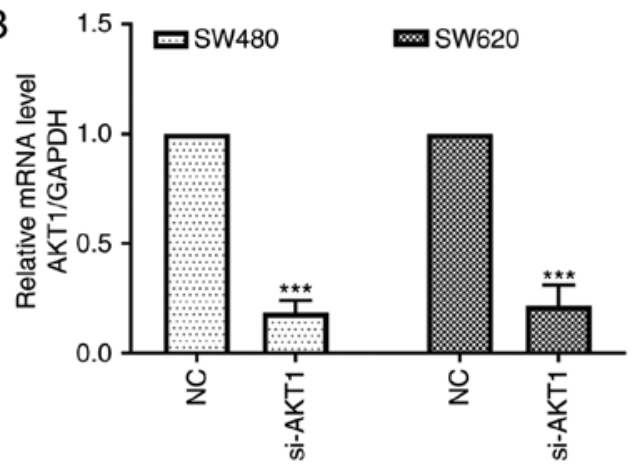

D

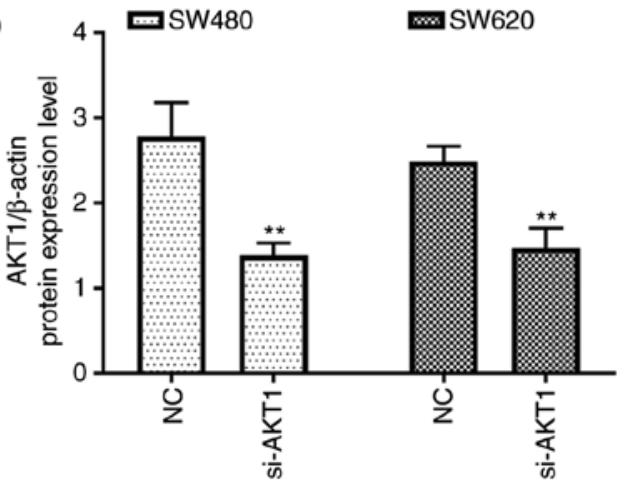

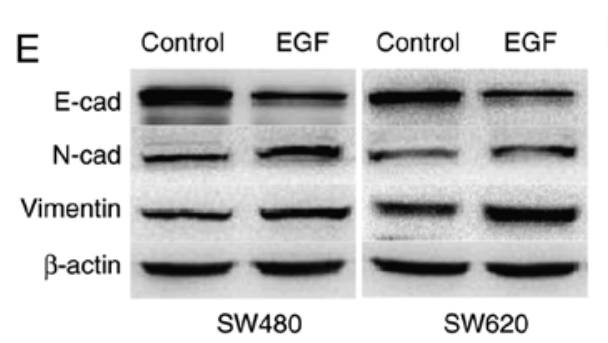
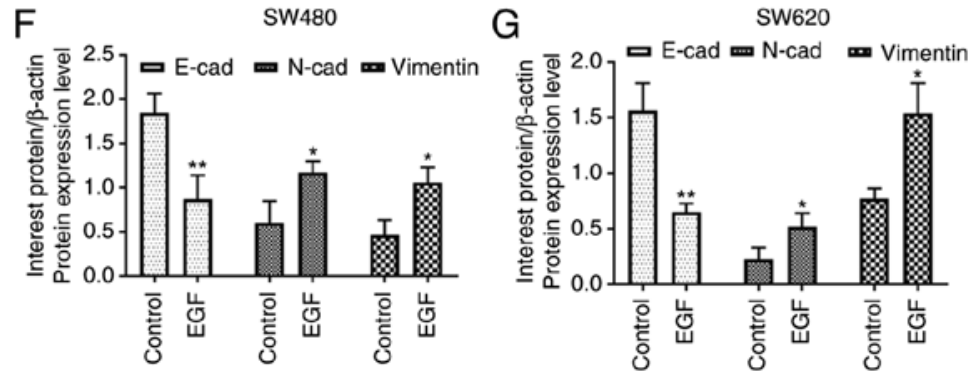

Figure 1. AKT1 is successfully knocked down in SW480 and SW620 cells, and EGF treatment induces EMT in both cell lines. (A) The knockdown efficiency of si-AKT1 sequence 1 was the highest and this was therefore selected for subsequent experiments. (B-D) Real-time quantitative polymerase chain reaction (qPCR) and western blotting revealed that the mRNA and protein expression of AKT1 in SW480 and SW620 cells transfected with si-AKT1 was significantly decreased compared with that in the two cell lines transfected with NC. (E-G) Western blotting revealed that E-cadherin expression in both cell lines was markedly downregulated after treatment with $50 \mathrm{ng} / \mathrm{ml}$ EGF for $48 \mathrm{~h}$, whereas the expression of $\mathrm{N}$-cadherin and vimentin was significantly upregulated. "P<0.05, ${ }^{* * *} \mathrm{P}<0.01,{ }^{* * * *} \mathrm{P}<0.001$, and NS $(\mathrm{P}>0.05)$ compared to the respective control; $\mathrm{n}=3$. These data were evaluated by one-way ANOVA. AKT1, serine/threonine kinase 1; EGF, epidermal growth factor; EMT, epithelial-mesenchymal transition; si-, small interfering-; NC, negative control; NS, not significant.
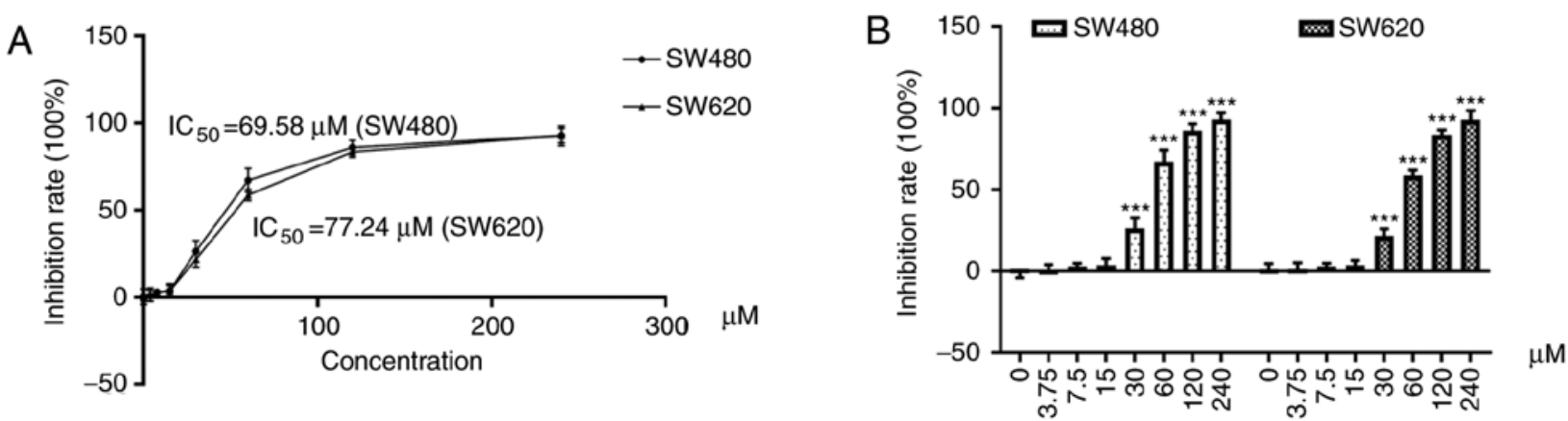

Figure 2. A Cell Counting Kit-8 (CCK-8) assay was performed to investigate the cytotoxic effects of resveratrol on SW480 and SW620 cells. (A) Cells were treated with resveratrol at doses of $0,3.75,7.5,15,30,60,120$, and $240 \mu \mathrm{M}$ and the inhibitory effects increased in a dose-dependent manner. The half maximal inhibitory concentration $\left(\mathrm{IC}_{50}\right)$ of resveratrol was $69.58 \mu \mathrm{M}$ in SW480 cells and $77.24 \mu \mathrm{M}$ in SW620 cells. (B) Resveratrol significantly decreased the survival rate of SW480 and SW620 cells at doses $>30 \mu \mathrm{M}$. The maximum nontoxic concentration of resveratrol was determined to be $15 \mu \mathrm{M}$ and this was used for subsequent experiments. ${ }^{* * * *} \mathrm{P}<0.001$ compared with the control; $\mathrm{n}=9$. These data were evaluated by one-way ANOVA. 
A

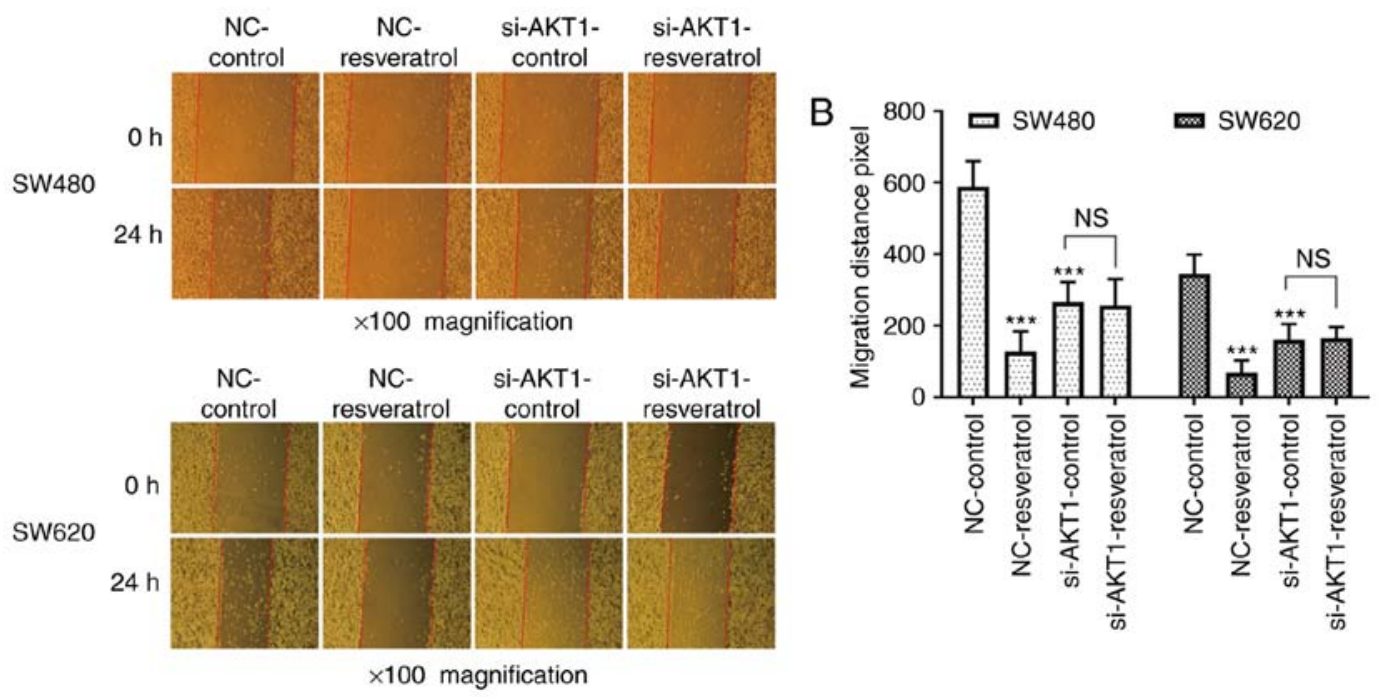

Figure 3. Resveratrol inhibits the migration of SW480 and SW620 cells in vitro. EGF (final concentration $50 \mathrm{ng} / \mathrm{ml}$ ) was added to cells in each group and treated for $48 \mathrm{~h}$ to induce EMT. Cells that were treated with $15 \mu \mathrm{M}$ resveratrol for $48 \mathrm{~h}$ were assigned to the NC-resveratrol and si-AKT1-resveratrol groups. Cells that were not treated with resveratrol were assigned to the NC-control and si-AKT1-control groups. (A and B) The scratch wound healing assay revealed that the 24-h migration distance of both cell lines in the NC-resveratrol and si-AKT1-control groups was notably shorter than that in the NC-control group. However, no significant difference was observed in the 24 -h migration distance between the si-AKT1-control and si-AKT1-resveratrol groups. ${ }^{* * *} \mathrm{P}<0.001$ and NS $(\mathrm{P}>0.05)$ compared with the NC group; $\mathrm{n}=9$. These data were evaluated by one-way ANOVA. EGF, epidermal growth factor; EMT, epithelial-mesenchymal transition; NC, negative control; si-, small interfering-; NS, not significant.
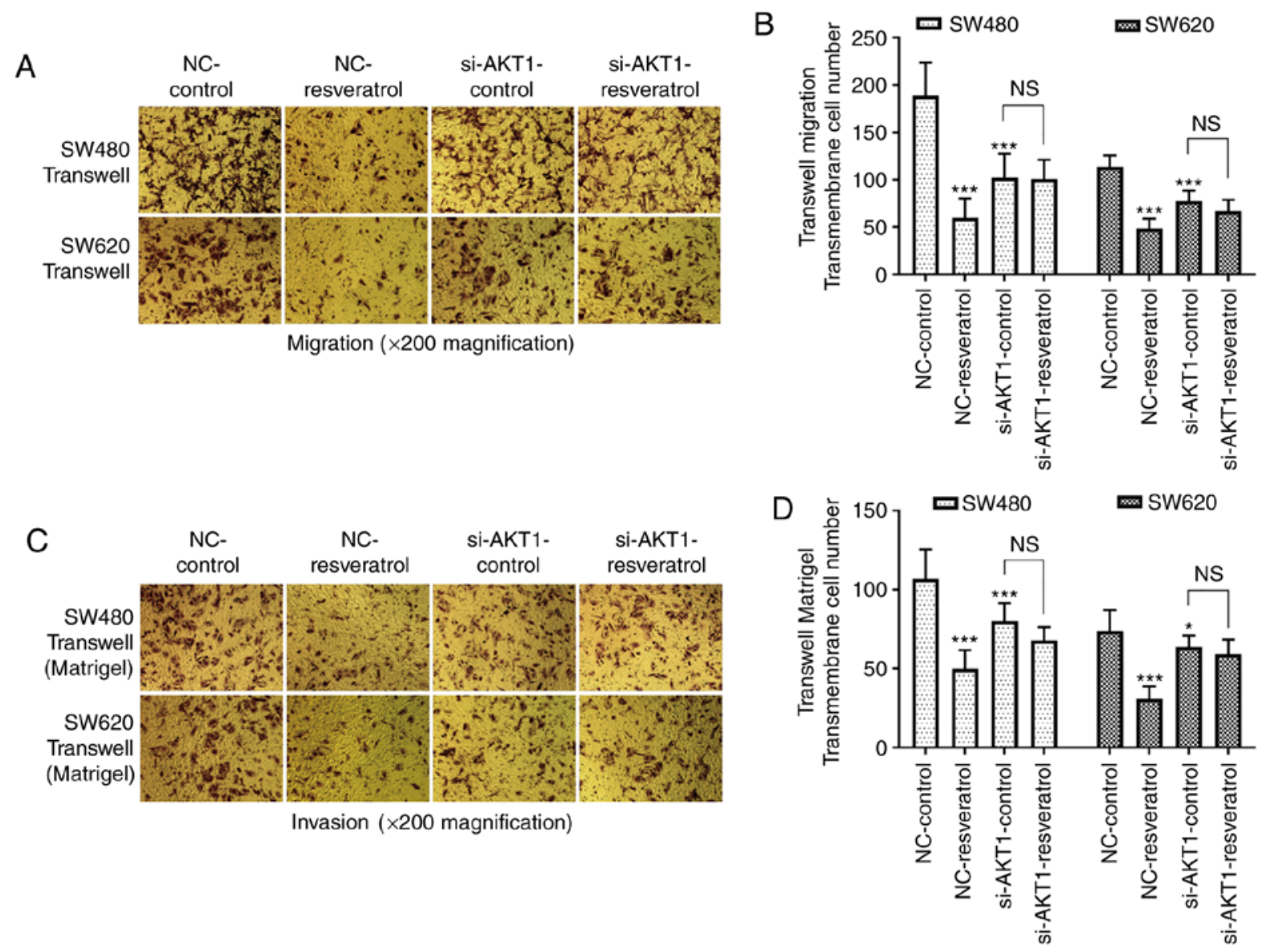

Figure 4. Resveratrol inhibits the migration and invasion of SW480 and SW620 cells in vitro. Cells were subjected to the same drug treatments as those used in the scratch wound healing assay. (A and B) Transwell migration assay revealing the migration of SW480 and SW620 cells subjected to various treatments. (C and D) Transwell invasion assay revealing the invasion of SW480 and SW620 cells subjected to various treatments. The number of migrated and invaded cells passing through the membrane in the NC-resveratrol and si-AKT1-control groups was significantly lower than that in the NC-control group. There was no significant difference between the number of migrated and invaded cells passing through the membrane in the si-AKT1-control and si-AKT1-resveratrol groups. ${ }^{*} \mathrm{P}<0.05,{ }^{* * * *} \mathrm{P}<0.001$, and NS $(\mathrm{P}>0.05)$ compared with the respective control; $\mathrm{n}=9$. These data were evaluated by one-way ANOVA. NC, negative control; si-, small interfering-; NS, not significant. 
A

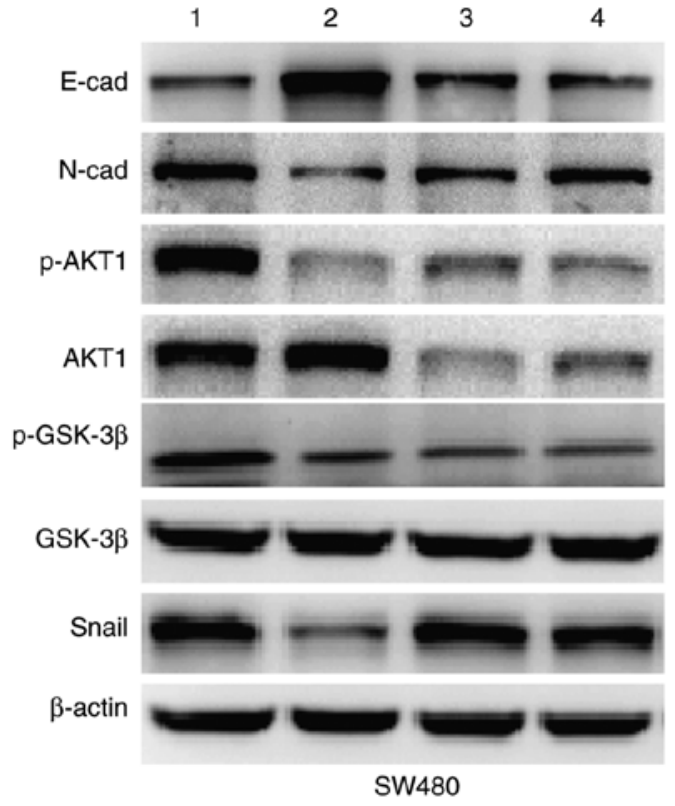

D

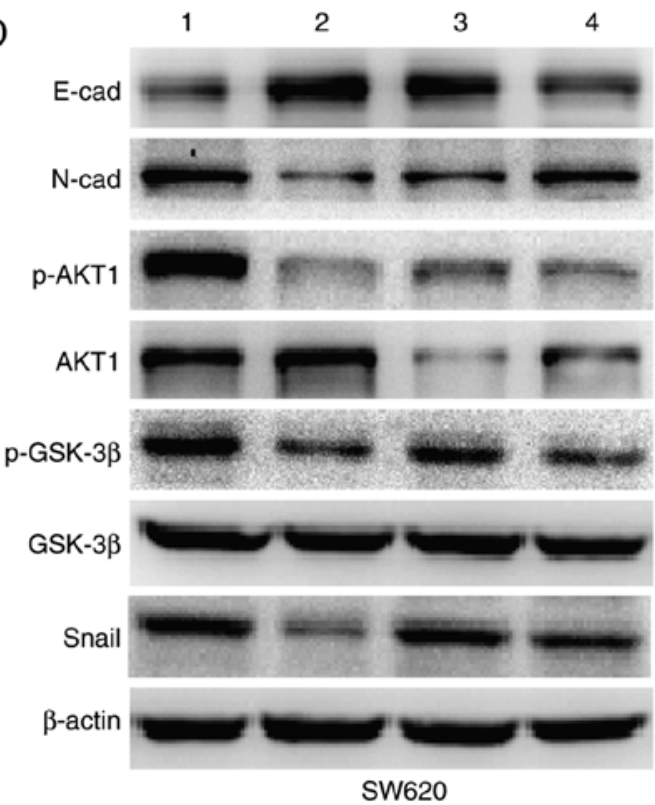

$\mathrm{B}$

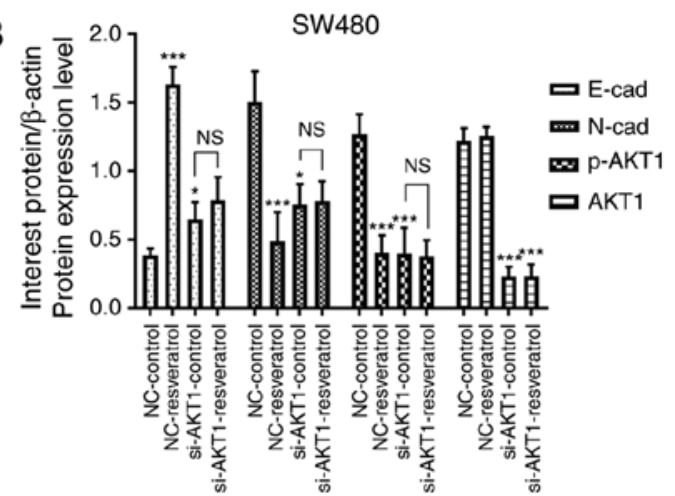

C

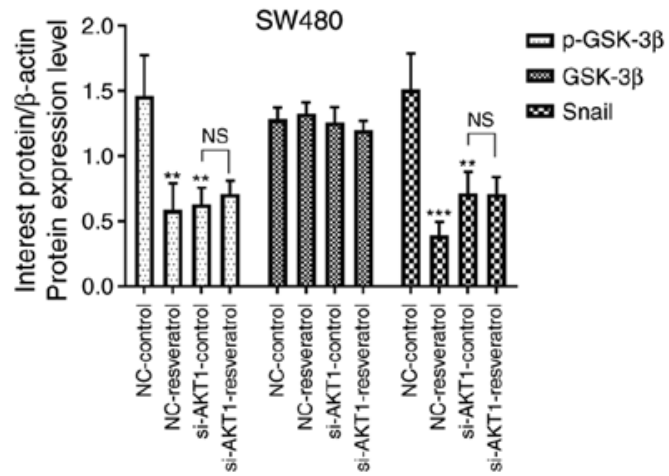

$\mathrm{E}$
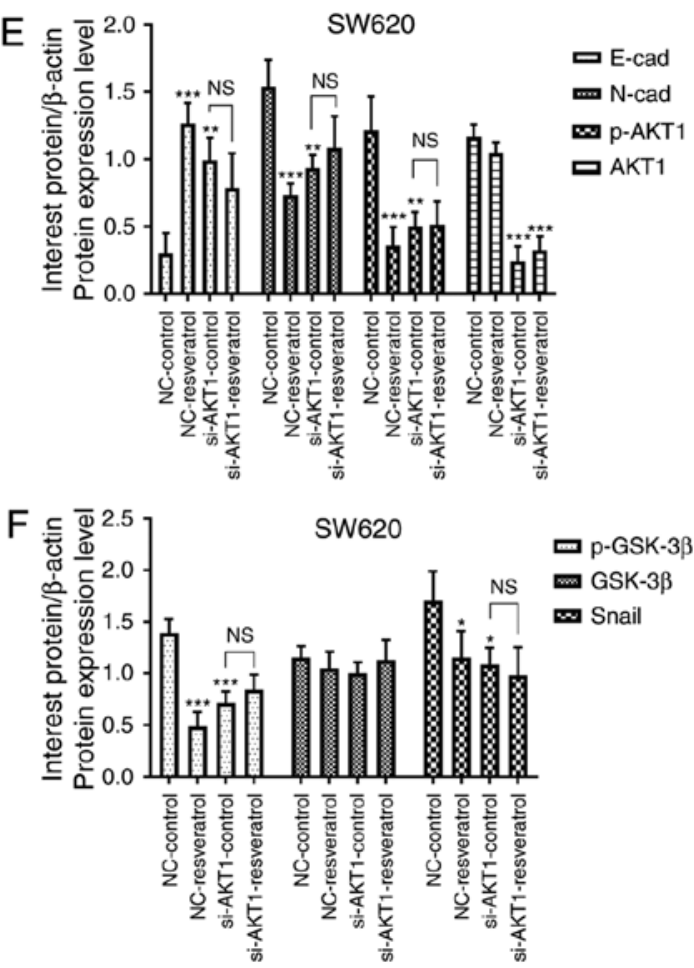

Figure 5. Resveratrol reverses EMT in colon cancer cells via regulation of the AKT/GSK-3 $\beta /$ Snail signaling pathway in vitro $(1=\mathrm{NC}-$ control, $2=\mathrm{NC}-$ resveratrol, $3=$ si-AKT1-control, 4=si-AKT1-resveratrol group). Cells were subjected to the same drug treatments as those used in the scratch wound healing assay.

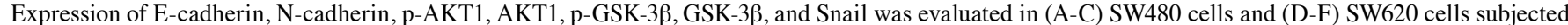
to various treatments via western blotting. In comparison with that in the NC-control group, E-cadherin expression was upregulated in the NC-resveratrol and si-AKT1-control groups, whereas the expression of N-cadherin, p-AKT, p-GSK-3 $\beta$, and Snail was downregulated. However, there was no difference in the expression of these proteins between the si-AKT1-resveratrol and si-AKT1-control groups. ${ }^{*} \mathrm{P}<0.05,{ }^{* *} \mathrm{P}<0.01,{ }^{* * * *} \mathrm{P}<0.001$, and NS $(\mathrm{P}>0.05)$ compared with the respective control; $n=3$. These data were evaluated by one-way ANOVA. EMT, epithelial-mesenchymal transition; GSK, glycogen synthase kinase; p-, phosphor-; NC, negative control; si-, small interfering-; NS, not significant.

was also significantly lower than that in the NC-control group $(\mathrm{P}<0.05$ and $\mathrm{P}<0.001)$, indicating that AKT1 knockdown also inhibited the migration and invasion of colon cancer cells.
However, there was no significant difference between the number of migrated and invaded cells passing through the membrane in the si-AKT1-control and si-AKT1-resveratrol 
groups ( $\mathrm{P}>0.05)$, indicating that the inhibitory effects of resveratrol on the migration and invasion of colon cancer cells were mitigated by AKT1 knockdown.

Resveratrol reverses EMT in colon cancer cells via regulation of the AKT/GSK-3//Snail signaling pathway in vitro. For further investigation of the effects of resveratrol on EMT in colon cancer cells as well as its downstream mechanisms, the expression of EMT markers and AKT/GSK-3 $\beta /$ Snail signaling pathway-related molecules were evaluated in SW480 and SW620 cells after treatment. As revealed by western blotting in Fig. 5A and D, the expression of E-cadherin in both cell lines was markedly upregulated in the NC-resveratrol and si-AKT1-control groups compared to the NC-control group, whereas N-cadherin, p-AKT1, p-GSK-3 $\beta$, and Snail expression was markedly downregulated. Densitometric analysis revealed consistent changes in the protein expression of the aforementioned genes after resveratrol treatment or AKT1 knockdown ( $\mathrm{P}<0.05, \mathrm{P}<0.01$ and $\mathrm{P}<0.001$, Fig. 5B, C, E and F). However, protein expression in SW480 and SW620 cells was not significantly different in the si-AKT1-resveratrol and si-AKT1-control groups, indicating that the effects of resveratrol on the reversal of EMT in colon cancer cells was markedly weakened or even nullified by AKT1 knockdown $(\mathrm{P}>0.05)$. These data indicated that resveratrol reversed EMT in colon cancer cells by regulating the AKT/GSK-3 $\beta /$ Snail signaling pathway.

Resveratrol treatment and AKT1 knockdown inhibit lung metastasis of colon cancer in vivo. Lung metastasis in nude mice was evaluated using live fluorescence imaging. The total flux in mice in the NC-resveratrol or si-AKT1-control groups was significantly lower than that in the NC-control group $(\mathrm{P}<0.01$ and $\mathrm{P}<0.001$, Fig. $6 \mathrm{~A}$ and $\mathrm{B})$, indicating that resveratrol treatment or AKT1 knockdown could inhibit lung metastasis of colon cancer. Consistent with the in vitro findings, no significant differences in total flux in the si-AKT1-control and si-AKT1-resveratrol groups were observed (Fig. 6A and B), indicating that resveratrol did not significantly inhibit lung metastasis of colon cancer after AKT1 knockdown. In addition, our animal experiments revealed that some nude mice did not have lung metastasis, while other nude mice had small or diffuse lung metastases, which could not be counted and measured. Since we could not separate the lung tumors alone, whole lung tissue was used for subsequent experiments. H\&E and immunohistochemical images of tumors were observed under a 200 -fold magnifying microscope. The total protein in the animal western blotting experiment was extracted from lung tissue.

Furthermore, H\&E staining revealed histopathological changes in tumor foci after treatment (Fig. 6C). The nuclei of tumor cells in the NC-control group were hypertrophic, deformed, intensely stained, and evidently heterogeneous and had several new tumor blood vessels. Tumor cell density, pathological mitotic phase, heteromorphic cells, and new tumor blood vessels were lower in the NC-resveratrol group than in the NC-control group. There was no difference between pathological mitosis and the number of heterotypic cells in the si-AKT1-control and si-AKT1-resveratrol groups. However, the si-AKT groups exhibited markedly lower pathological mitosis, number of heteromorphic cells, and new tumor blood vessels than those in the $\mathrm{NC}$-control group.

Resveratrol reverses EMT in the tumor tissues of nude

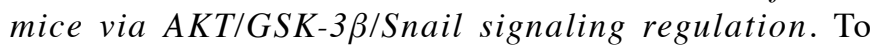
further confirm whether resveratrol inhibited lung metastasis of colon cancer in vivo via the AKT/GSK-3 $\beta /$ Snail signaling pathway, western blot and immunohistochemical staining assays were performed to detect the expression of EMT-markers as well as that of AKT/GSK-3 $\beta /$ Snail signaling pathway-related molecules in the tumor tissues of nude mice. Western blotting (Fig. 7) and immunohistochemical staining (Fig. 8) assays revealed consistent results. E-cadherin expression was upregulated in the NC-resveratrol and si-AKT1-control groups compared to the NC-control group, whereas the expression of $\mathrm{N}$-cadherin, p-AKT, p-GSK-3 $\beta$, and Snail was downregulated $(\mathrm{P}<0.05$ and $\mathrm{P}<0.01$, Figs. 7 and 8 ), indicating that resveratrol and AKT1 knockdown could reverse EMT in colon cancer cells in tumor tissues and promote the transformation of colon cancer cells from mesenchymal to epithelial phenotypes. However, there was no difference in the expression of these proteins in the si-AKT1-resveratrol and si-AKT1-control groups ( $\mathrm{P}>0.05$, Figs. 7 and 8 ), further confirming that the ability of resveratrol to reverse EMT in colon cancer cells in tumor tissues almost disappeared after AKT1 knockdown.

\section{Discussion}

At present, CRC is a malignant tumor that occurs with a high incidence rate. Following the application of comprehensive treatments, such as surgery, radiotherapy, chemotherapy, and targeted therapies, the clinical cure rate of CRC has clearly improved, although the 5-year survival rate of patients with CRC with distant metastases remains low (4). Therefore, inhibition of invasion and metastasis is a key step in the treatment of CRC. Traditional Chinese medicine (TCM) compounds, which have been systematically developed through continuous refinement and practice over thousands of years offer the unique advantage of low toxicity and side effects and can suppress the invasion and metastasis of CRC $(27,28)$. The identification of effective TCM compounds for the treatment of CRC is of great importance.

Resveratrol is a natural polyphenol compound that has several therapeutic effects (29). Several studies have confirmed that resveratrol inhibits tumor invasion and metastasis (30-33). Consistent with these findings, it was confirmed that resveratrol suppressed the migration and invasion of colon cancer cells both in vitro and in vivo. It is well established that EMT leads to the loss of adhesion between tumor cells and is therefore a regulator of tumor invasion and metastasis (34). Several studies have revealed that resveratrol can also regulate the occurrence and development of EMT. Resveratrol inhibited EMT by increasing miR-200c expression in colon cancer cells, subsequently inhibiting the invasion and metastasis of colon cancer cells (35). Resveratrol may also inhibit EMT in colon cancer cells through increased E-cadherin expression and reduced vimentin expression, thus, enhancing the sensitivity of colon cancer cells to chemotherapeutic drugs (36). The 
A

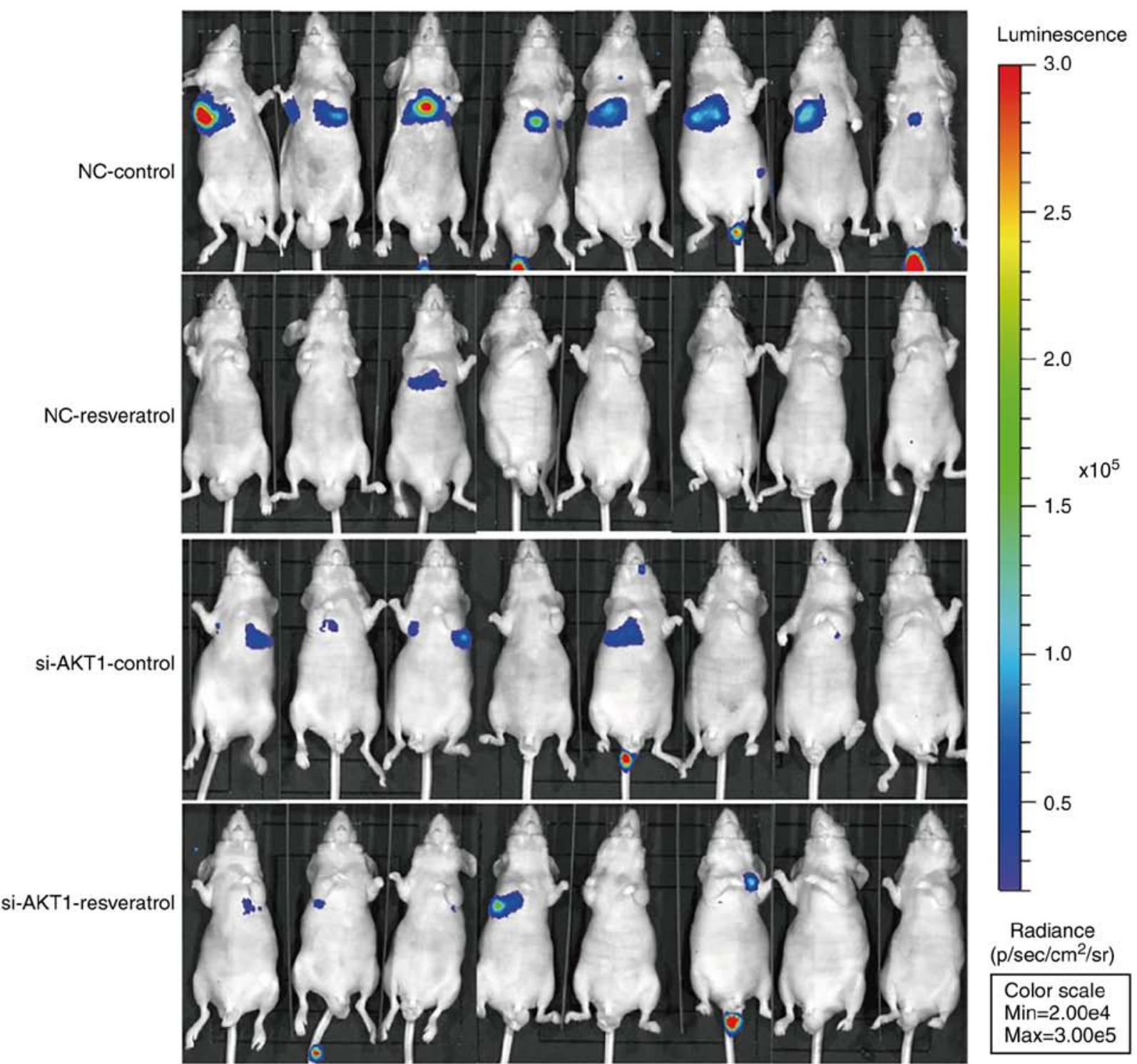

\section{B}

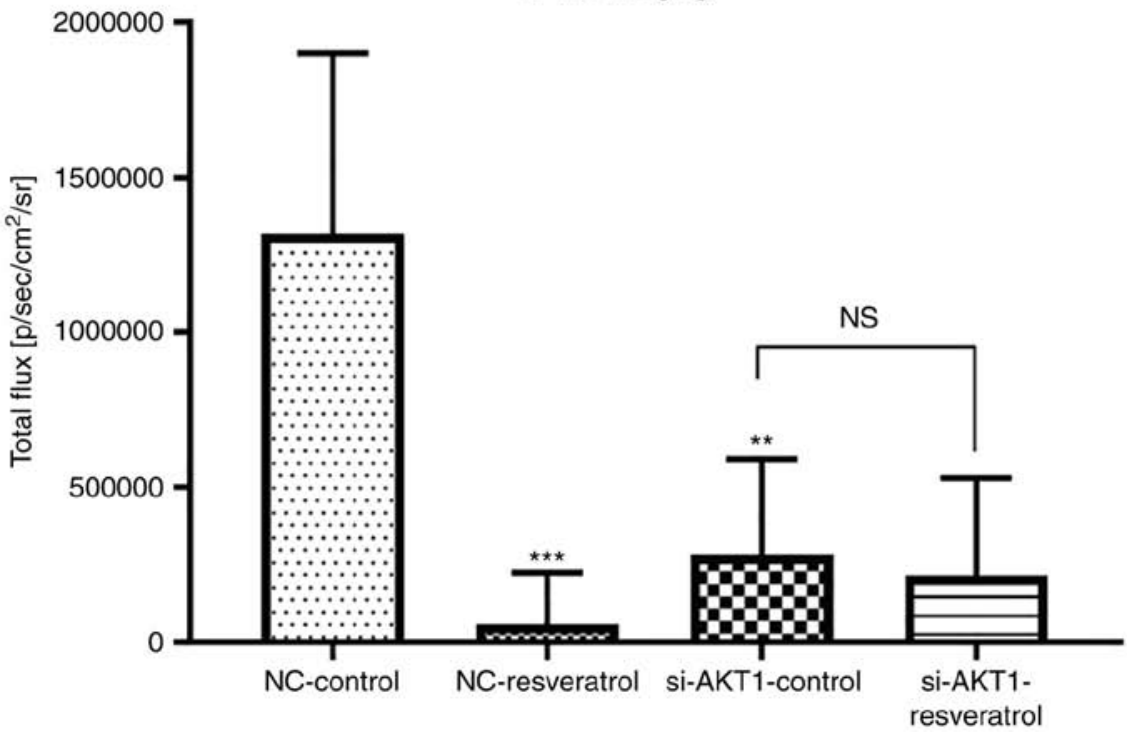

Figure 6. Resveratrol inhibits the lung metastasis of colon cancer in vivo and results in histopathological changes in the tumor foci in mice. Nude mice in the resveratrol groups were administered $150 \mathrm{mg} / \mathrm{kg}$ resveratrol once daily via oral gavage for 2 weeks. Mice in the control groups received an equal volume of normal saline once daily for 2 weeks. (A and B) Live fluorescence imaging revealing lung metastasis of colon cancer in mice administered different treatments. The total flux of mice in the NC-resveratrol and si-AKT1-control groups was significantly lower than that in the NC-control group. Consistent with in vitro findings, there was also no significant difference between the total flux in the si-AKT1-control and si-AKT1-resveratrol groups. ${ }^{* * *} \mathrm{P}<0.01,{ }^{* * * *} \mathrm{P}<0.001$ vs. NC-control.. 

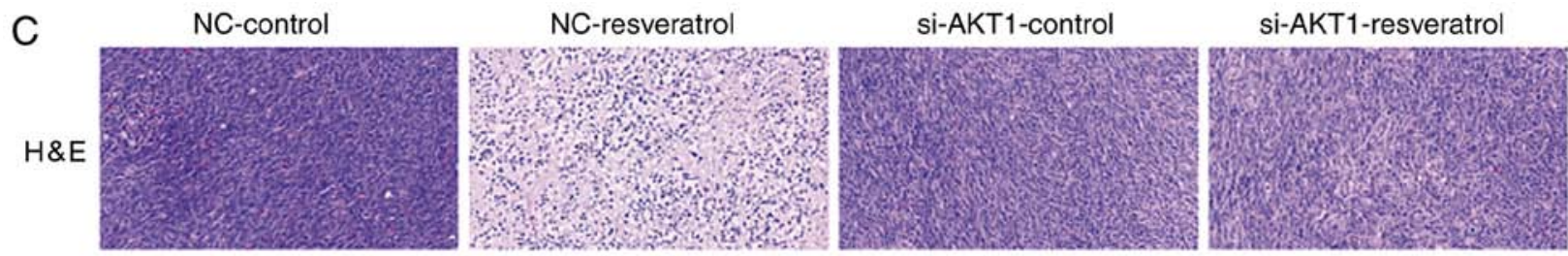

$\times 200$ magnification

Figure 6. Continued. (C) H\&E staining revealed histopathological changes in the tumor foci of mice administered different treatments. ${ }^{* *} \mathrm{P}<0.01,{ }^{* * * *} \mathrm{P}<0.001$, and NS ( $\mathrm{P}>0.05)$ compared with the respective control; $\mathrm{n}=8$. These data were evaluated by independent samples-nonparametric tests. $\mathrm{NC}$, negative control; si-, small interfering-; H\&E, hematoxylin and eosin.

A
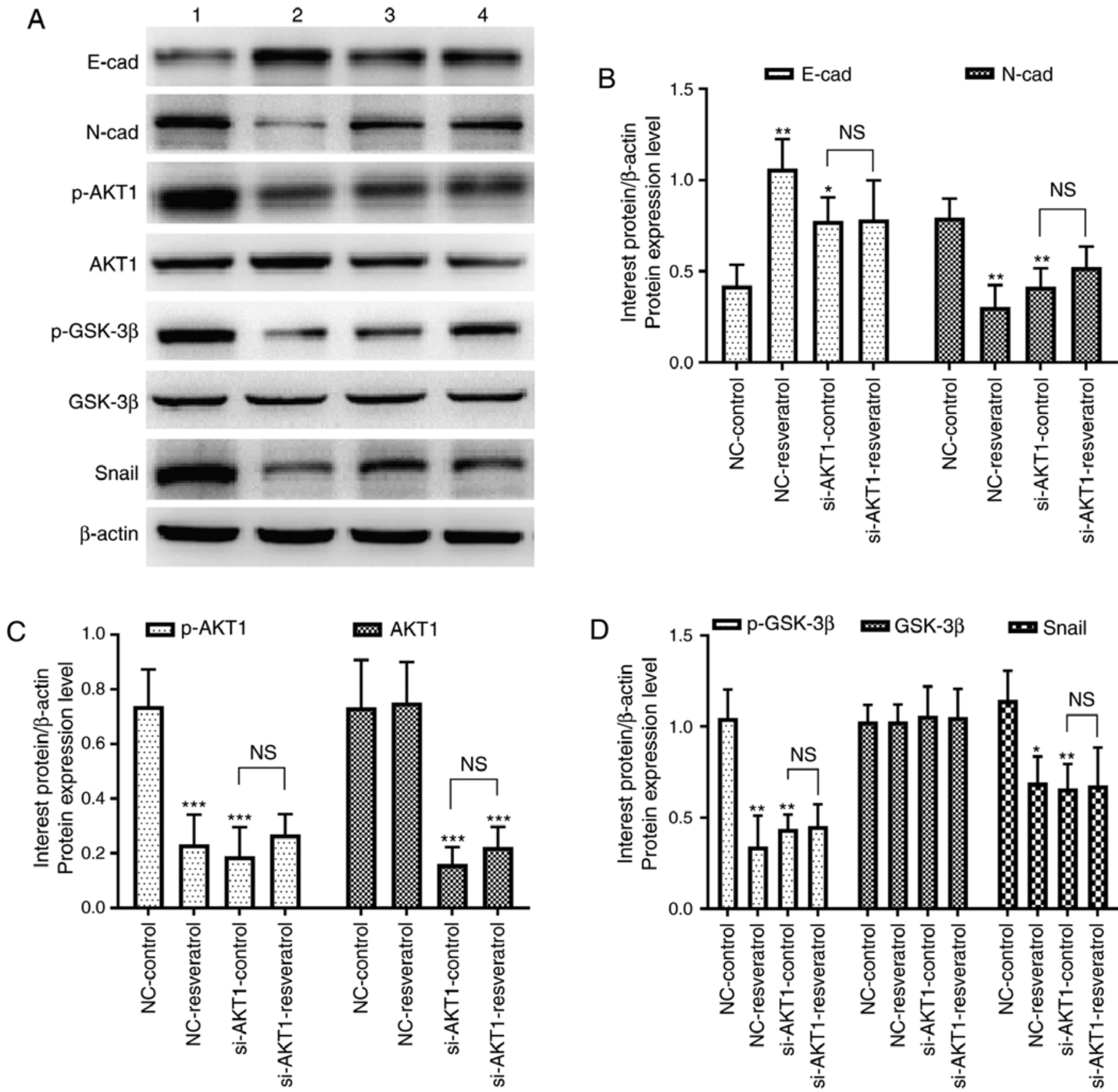

Figure 7. Resveratrol reverses EMT in colon cancer cells via regulation of the AKT/GSK-3 $\beta /$ Snail signaling pathway in vivo $(1=\mathrm{NC}$-control, $2=\mathrm{NC}$-resveratrol, $3=$ si-AKT1-control, 4=si-AKT1-resveratrol group). (A-D) Western blotting was performed to assess the expression of E-cadherin, N-cadherin, p-AKT1, AKT1, p-GSK-3 $\beta$, GSK-3 $\beta$, and Snail in mice administered various treatments. In comparison with that in the NC-control group, E-cadherin expression was upregulated in the NC-resveratrol and si-AKT1-control groups, whereas the expression of N-cadherin, p-AKT, p-GSK-3 $\beta$, and Snail was downregulated. However, there was no difference between the expression of these proteins in the si-AKT1-resveratrol and si-AKT1-control groups. ${ }^{*} \mathrm{P}<0.05,{ }^{* * *} \mathrm{P}<0.01,{ }^{* * * *} \mathrm{P}<0.001$, and NS $(\mathrm{P}>0.05)$ compared with the respective control; $\mathrm{n}=3$. These data were evaluated by one-way ANOVA. EMT, epithelial-mesenchymal transition; GSK, glycogen synthase kinase; NC, negative control; si-, small interfering-; p-, phosphor-; NS, not significant. 

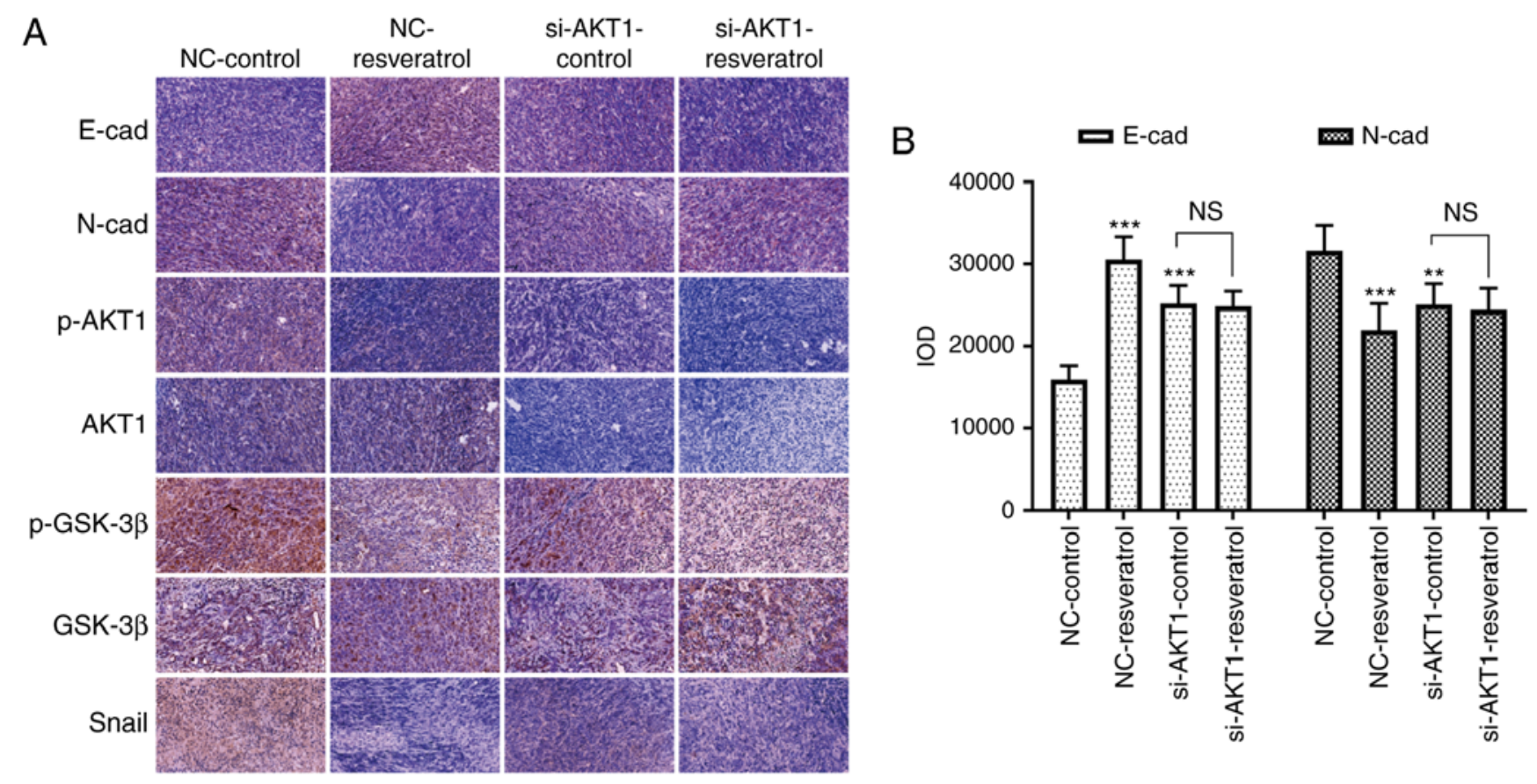

$200 \times$ magnification
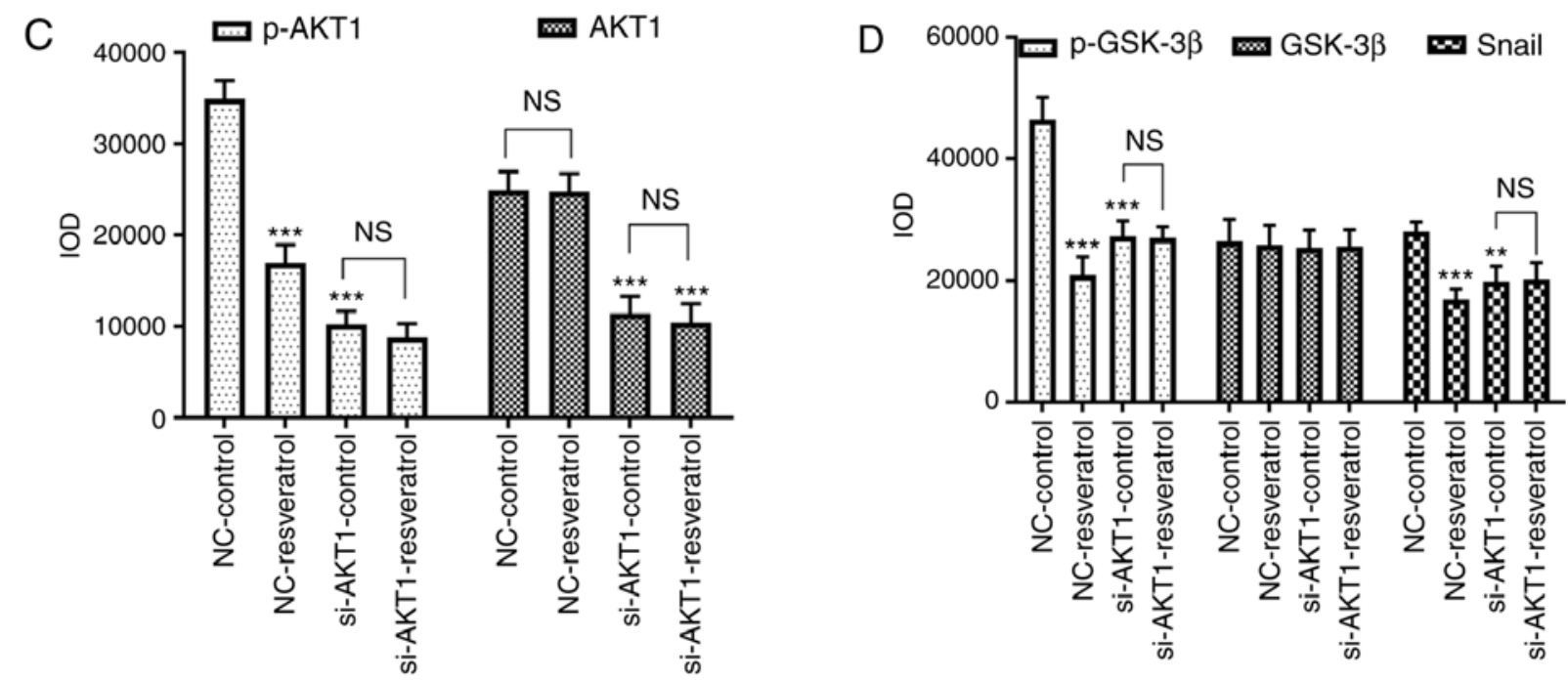

Figure 8. Resveratrol reverses EMT in colon cancer cells via regulation of the AKT/GSK-3 $\beta /$ Snail signaling pathway in vivo. (A-D) Immunohistochemical

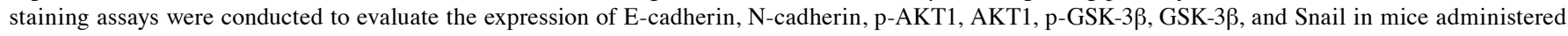
different treatments. In comparison with that in the NC-control group, E-cadherin expression was upregulated in the NC-resveratrol and si-AKT1-control groups, whereas the expression of N-cadherin, p-AKT, p-GSK-3 $\beta$, and Snail was downregulated. However, there was no difference between the expression of these proteins in the si-AKT1-resveratrol and si-AKT1-control groups. ${ }^{* *} \mathrm{P}<0.01,{ }^{* * *} \mathrm{P}<0.001$, and $\mathrm{NS}(\mathrm{P}>0.05)$ compared with the respective control; $\mathrm{n}=6$. These data were evaluated by one-way ANOVA. EMT, epithelial-mesenchymal transition; GSK, glycogen synthase kinase; p-, phosphor-; NC, negative control; si-, small interfering-; NS, not significant.

present study revealed that E-cadherin was upregulated and $\mathrm{N}$-cadherin was downregulated by resveratrol treatment. Since the dysregulation of E-cadherin and N-cadherin is an important characteristic of EMT (37), it was confirmed that resveratrol regulated EMT in colon cancer cells to inhibit the invasion and metastasis of colon cancer.

Furthermore, the AKT/GSK-3 $\beta /$ Snail signaling pathway is a key mechanism that modulates tumor invasion and metastasis. Jiang et al demonstrated that phosphoinositide 3-kinase (PI3K)/AKT/GSK-3 $\beta /$ Snail signaling was involved in the invasion and metastasis of hepatocellular carcinoma cells (20). Zhang et al (38) revealed that cytosolic THUMP domain-containing 1 (THUMPD1) facilitated the invasion and metastasis of breast cancer cells though regulation of the AKT/GSK-3 $\beta /$ Snail signaling pathway. Notably, tumor-derived C-X-C motif chemokine ligand 5 (CXCL5) was revealed to promote the metastasis of CRC via activation of the AKT/GSK3 $\beta / \beta$-catenin pathway (39). In the present study, AKT1 knockdown markedly inhibited cell migration and invasion, reversed EMT, and activated AKT1/GSK-3 $\beta /$ Snail signaling in colon cancer cells. Moreover, the effects of resveratrol were weakened or even nullified after AKT1 knockdown. 
Therefore, resveratrol may regulate EMT in colon cancer cells and inhibit the invasion and metastasis of colon cancer through the AKT1/GSK-3ק/Snail signaling pathway.

In conclusion, resveratrol may inhibit the invasion and metastasis of colon cancer cells through reversal of EMT via the AKT/GSK-3 $\beta /$ Snail signaling pathway. AKT1 may be a key regulator of EMT in colon cancer cells and serve as a potential therapeutic target for this disease.

\section{Acknowledgements}

Not applicable.

\section{Funding}

The present study was sponsored by the Natural Science Foundation of Zhejiang Province (LQ17H290002, LY17H270007), the Zhejiang Provincial TCM Scientific Research Fund project (2019ZQ015, 2017ZA048), the National Natural Science Foundation of China (81573902), the Zhejiang Provincial Medical and Health Science and Technology project (2017KY119), the China Postdoctoral Science Foundation (2017M612040, 2018T110610), the Program for the Cultivation of Youth Talents in China Association of Chinese Medicine (QNRC2-C08), the Zhejiang Provincial Program for the Cultivation of High-Level Innovative Health Talents (2015-43) and the Zhejiang Provincial Project for the Key Discipline of Traditional Chinese Medicine (2017-XK-A09).

\section{Availability of data and materials}

The datasets used and/or analyzed during the present study are available from the corresponding author on reasonable request.

\section{Authors' contributions}

SR conceived the study and acquired the funding. LY and $\mathrm{MZ}$ conceived and designed the experiments. LY, MZ, KZ, LS and DH collected samples and conducted the experiments. MS, SM, HH and HSW performed the genome assembly and analysis of the data. All authors have read and approved the final manuscript and agree to be accountable for all aspects of the research in ensuring that the accuracy or integrity of any part of the work are appropriately investigated and resolved.

\section{Ethics approval and consent to participate}

All animal experiments were approved by the Institutional Animal Care and Use Committee of Zhejiang Chinese Medical University. The procedures were conducted according to the protocol for experimentation with animals (NIH Publication no. 85-23, revised 1996).

\section{Patient consent for publication}

Not applicable.

\section{Competing interests}

The authors declare that they have no competing interests.

\section{References}

1. Torre LA, Bray F, Siegel RL, Ferlay J, Lortet-Tieulent J and Jemal A: Global cancer statistics, 2012. CA Cancer J Clin 65: 87-108, 2015.

2. Siegel RL, Miller KD and Jemal A: Cancer statistics, 2017. CA Cancer J Clin 67: 7-30, 2017.

3. Arnold M, Sierra MS, Laversanne M, Soerjomataram I, Jemal A and Bray F: Global patterns and trends in colorectal cancer incidence and mortality. Gut 66: 683-691, 2017.

4. Siegel RL, Miller KD, Fedewa SA, Ahnen DJ, Meester RGS Barzi A and Jemal A: Colorectal cancer statistics, 2017. CA Cancer J Clin 67: 177-193, 2017.

5. Liang WC, Fu WM, Wong CW, Wang Y, Wang WM, Hu GX, Zhang L, Xiao LJ, Wan DC, Zhang JF and Waye MM: The lncRNA H19 promotes epithelial to mesenchymal transition by functioning as miRNA sponges in colorectal cancer. Oncotarget 6: 22513-22525, 2015.

6. Edwards BK, Ward E, Kohler BA, Eheman C, Zauber AG, Anderson RN, Jemal A, Schymura MJ, Lansdorp-Vogelaar I, Seeff LC, et al: Annual report to the nation on the status of cancer, 1975-2006, featuring colorectal cancer trends and impact of interventions (risk factors, screening, and treatment) to reduce future rates. Cancer 116: 544-573, 2010.

7. Diepenbruck M and Christofori G: Epithelial-mesenchymal transition (EMT) and metastasis: Yes, no, maybe? Curr Opin Cell Biol 43: 7-13, 2016.

8. Vences-Catalan F and Levy S: Immune targeting of tetraspanins involved in cell invasion and metastasis. Front Immunol 9: 1277, 2018.

9. Carter LG, D'Orazio JA and Pearson KJ: Resveratrol and cancer: Focus on in vivo evidence. Endocr Relat Cancer 21: R209-R225, 2014.

10. Borriello A: Resveratrol in cancer prevention and treatment: Focusing on molecular targets and mechanism of action. Proceedings 1: 976, 2017.

11. Kim SE, Shin SH, Lee JY, Kim CH, Chung IK, Kang HM, Park HR, Park BS and Kim IR: Resveratrol induces mitochondrial apoptosis and inhibits epithelial-mesenchymal transition in oral squamous cell carcinoma cells. Nutr Cancer 70: 125-135, 2018.

12. Cilibrasi C, Riva G, Romano G, Cadamuro M, Bazzoni R, Butta V, Paoletta L, Dalprà L, Strazzabosco M, Lavitrano M, et al: Resveratrol impairs glioma stem cells proliferation and motility by modulating the wnt signaling pathway. PLoS One 12: e0169854, 2017.

13. Li W, Ma J, Ma Q, Li B, Han L, Liu J, Xu Q, Duan W, Yu S, Wang $\mathrm{F}$ and $\mathrm{Wu}$ E: Resveratrol inhibits the epithelial-mesenchymal transition of pancreatic cancer cells via suppression of the PI-3K/Akt/NF- $\kappa B$ pathway. Curr Med Chem 20: 4185-4194, 2013.

14. Aiello NM, Maddipati R, Norgard RJ, Balli D, Li J, Yuan S, Yamazoe T, Black T, Sahmoud A, Furth EE, et al: EMT subtype influences epithelial plasticity and mode of cell migration. Dev Cell 45: 681-695.e684, 2018.

15. Zhang H, Sun JD, Yan LJ and Zhao XP: PDGF-D/PDGFR $\beta$ promotes tongue squamous carcinoma cell (TSCC) progression via activating p38/AKT/ERK/EMT signal pathway. Biochem Biophys Res Commun 478: 845-851, 2016.

16. Saegusa M,Hashimura M,Kuwata T and Okayasu I: Requirement of the Akt/beta-catenin pathway for uterine carcinosarcoma genesis, modulating E-cadherin expression through the transactivation of slug. Am J Pathol 174: 2107-2115, 2009.

17. Tokunaga E, Oki E, Egashira A, Sadanaga N, Morita M, Kakeji Y and Maehara Y: Deregulation of the Akt pathway in human cancer. Curr Cancer Drug Targets 8: 27-36, 2008.

18. Dou Y, Lei JQ, Guo SL, Zhao D, Yue HM and Yu Q: The CNPY2 enhances epithelial-mesenchymal transition via activating the AKT/GSK3 $\beta$ pathway in non-small cell lung cancer. Cell Biol Int 42: 959-964, 2018.

19. Lu LL, Chen XH, Zhang G, Liu ZC, Wu N, Wang H, Qi YF, Wang HS, Cai SH and Du J: CCL21 facilitates chemoresistance and cancer stem cell-like properties of colorectal cancer cells through AKT/GSK-3 $\beta /$ snail signals. Oxid Med Cell Longev 2016: 5874127, 2016.

20. Jiang H, Zhou Z, Jin S, Xu K, Zhang H, Xu J, Sun Q, Wang J and Xu J: PRMT9 promotes hepatocellular carcinoma invasion and metastasis via activating PI3K/Akt/GSK-3 $\beta /$ Snail signaling. Cancer Sci 109: 1414-1427, 2018. 
21. Matsumoto T, Yokoi A, Hashimura M, Oguri Y, Akiya M and Saegusa M: TGF- $\beta$-mediated LEFTY/Akt/GSK-3 $\beta /$ Snail axis modulates epithelial-mesenchymal transition and cancer stem cell properties in ovarian clear cell carcinomas. Mol Carcinog 57: 957-967, 2018.

22. Li Y, Lin Z, Chen B, Chen S, Jiang Z, Zhou T, Hou Z and Wang Y: Ezrin/NF-kB activation regulates epithelial- mesenchymal transition induced by EGF and promotes metastasis of colorectal cancer. Biomed Pharmacother 92: 140-148, 2017.

23. Liu ZC, Chen XH, Song HX, Wang HS, Zhang G, Wang H, Chen DY, Fang R, Liu H, Cai SH and Du J: Snail regulated by PKC/GSK-3 $\beta$ pathway is crucial for EGF-induced epithelial-mesenchymal transition (EMT) of cancer cells. Cell Tissue Res 358: 491-502, 2014.

24. Livak KJ and Schmittgen TD: Analysis of relative gene expression data using real-time quantitative PCR and the 2(-Delta Delta C(T)) method. Methods 25: 402-408, 2001

25. Shimaoka H, Takeno S, Maki K, Sasaki T, Hasegawa S and Yamashita Y: A cytokine signal inhibitor for rheumatoid arthritis enhances cancer metastasis via depletion of NK cells in an experimental lung metastasis mouse model of colon cancer. Oncol Lett 14: 3019-3027, 2017.

26. Mateo-Lozano S, Bazzocco S, Rodrigues P, Mazzolini R, Andretta E, Dopeso H, Fernández Y, Del Llano E, Bilic J, Suárez-López L, et al: Loss of the EPH receptor B6 contributes to colorectal cancer metastasis. Sci Rep 7: 43702, 2017.

27. Liu X, Ji Q, Deng W, Chai N, Feng Y, Zhou L, Sui H, Li C, Sun X and Li Q: JianPi JieDu recipe inhibits epithelial-to-mesenchymal transition in colorectal cancer through TGF- $\beta /$ Smad mediated Snail/E-cadherin expression. Biomed Res Int 2017: 2613198, 2017.

28. Zhang Z, Chen H, Xu C, Song L, Huang L, Lai Y, Wang Y, Chen H, Gu D, Ren L and Yao Q: Curcumin inhibits tumor epithelialmesenchymal transition by downregulating the Wnt signaling pathway and upregulating NKD2 expression in colon cancer cells. Oncol Rep 35: 2615-2623, 2016.

29. Berman AY, Motechin RA, Wiesenfeld MY and Holz MK: The therapeutic potential of resveratrol: A review of clinical trials. NPJ Precis Oncol 1: 35, 2017

30. Gao Q, Yuan Y, Gan HZ and Peng Q: Resveratrol inhibits the hedgehog signaling pathway and epithelial-mesenchymal transition and suppresses gastric cancer invasion and metastasis. Oncol Lett 9: 2381-2387, 2015 .
31. Jiao Y, Li H, Liu Y, Guo A, Xu X, Qu X, Wang S, Zhao J, Li Y and Cao Y: Resveratrol inhibits the invasion of glioblastoma-initiating cells via down-regulation of the PI3K/Akt/NF- $\kappa \mathrm{B}$ signaling pathway. Nutrients 7: 4383-4402, 2015.

32. Kim YS, Sull JW and Sung HJ: Suppressing effect of resveratrol on the migration and invasion of human metastatic lung and cervical cancer cells. Mol Biol Rep 39: 8709-8716, 2012.

33. Ji Q, Liu X, Fu X, Zhang L, Sui H, Zhou L, Sun J, Cai J, Qin J, Ren $\mathrm{J}$ and Li Q: Resveratrol inhibits invasion and metastasis of colorectal cancer cells via MALAT1 mediated Wnt/ $\beta$-catenin signal pathway. Plos One 8: e78700, 2013.

34. Ombrato L and Malanchi I: The EMT universe: Space between cancer cell dissemination and metastasis initiation. Crit Rev Oncog 19: 349-361, 2014.

35. Karimi Dermani F, Saidijam M, Amini R, Mahdavinezhad A, Heydari K and Najafi R: Resveratrol inhibits proliferation, invasion, and epithelial-mesenchymal transition by increasing miR-200c expression in HCT-116 colorectal cancer cells. J Cell Biochem 118: 1547-1555, 2017.

36. Buhrmann C, Shayan P, Kraehe P,Popper B, Goel A and Shakibaei M: Resveratrol induces chemosensitization to 5-fluorouracil through up-regulation of intercellular junctions, Epithelial-to-mesenchymal transition and apoptosis in colorectal cancer. Biochem Pharmacol 98 51-68, 2015

37. Ye X and Weinberg RA: Epithelial-mesenchymal plasticity: A central regulator of cancer progression. Trends Cell Biol 25: 675-686, 2015 .

38. Zhang X, Jiang G, Sun M, Zhou H, Miao Y, Liang M, Wang E and Zhang Y: Cytosolic THUMPD1 promotes breast cancer cells invasion and metastasis via the AKT-GSK3-Snail pathway. Oncotarget 8: 13357-13366, 2017.

39. Zhao J, Ou B, Han D, Wang P, Zong Y, Zhu C, Liu D, Zheng M, Sun J, Feng $\mathrm{H}$ and Lu A: Tumor-derived CXCL5 promotes human colorectal cancer metastasis through activation of the ERK/Elk-1/Snail and AKT/GSK3//3-catenin pathways. Mol Cancer 16: 70, 2017.

This work is licensed under a Creative Commons Attribution-NonCommercial-NoDerivatives 4.0 International (CC BY-NC-ND 4.0) License. 